\title{
Avaliação comparativa das atividades de microcrédito \\ Brasil e Bolívia
}

Franco de Matos $^{1}$

\begin{abstract}
The objective of this study is to make a comparison between Brazilian and Bolivian microfinance activities. An indicator, which summarizes the main policies of each country and their respective institutional systems, will do this comparison. The indicator's criteria are based on the feedback of the microfinance instruments with respect to information asymmetries related to credit market. These asymmetries are able to exclude low income and borrowed constrained entrepreneurs.
\end{abstract}

Key Words: Microfinance, Information Asymmetries, Efficacy Indicator.

\section{Resumo}

O objetivo deste artigo é proceder a uma avaliação comparativa da atividade de microcrédito entre Brasil e Bolívia. Esta avaliação se fará a partir da proposição e aplicação de um indicador capaz de sistematizar o cotejamento das principais iniciativas de cada país e seus respectivos arcabouços institucionais. Os critérios que permitirão a avaliação estarão embasados nas respostas que os instrumentos de microcrédito fornecem aos problemas relacionados à assimetria de informação subjacente ao mercado de crédito que excluem empreendedores de baixa renda ou sem garantias reais do acesso ao crédito.

Palavras-chave: Microcrédito, Assimetria de Informação, Indicador de Eficácia.

\footnotetext{
${ }^{1}$ Ensaio elaborado a partir de dissertação defendida no PROLAM/USP, em junho de 2002. Linha de pesquisa: Sociedade, Economia e Estado; Orientadora: Profa. Dra. Maria Cristina Cacciamali, Coorientador: Prof. Dr. Márcio Bobik Braga. E-mail: francomt@uol.com.br.
} 


\section{Introdução}

Atividades de microcrédito constituem-se serviços de intermediação financeira direcionados para populações de baixa renda, possibilitando-lhes acesso ao crédito e consequente desenvolvimento de seus empreendimentos econômicos. São preponderantemente ofertadas por iniciativas locais, provenientes de ações da sociedade civil (principalmente ONGs - Organizações não Governamentais), do poder público em qualquer de suas esferas (sendo mais usual a municipal ou local), instituições bancárias ou financeiras, além de parcerias entre esses agentes (organizações de controle misto). Estas iniciativas são denominadas organizações de microcrédito, também apresentadas pela literatura como serviços de microfinanças, instituições de crédito popular ou Bancos do Povo. Em diversos países estas organizações não estão enquadradas na legislação do sistema financeiro. Juridicamente são constituídas como associações civis sem fins lucrativos ou projetos/programas governamentais (Ledgerwood, 1999).

O desenvolvimento deste tipo de serviço financeiro está respaldado nas soluções que apresenta para problemas relacionados à assimetria de informação no mercado de crédito. O sistema financeiro convencional depara-se com dificuldades inerentes à seleção de tomadores de empréstimos que se dediquem a empreendimentos viáveis (com baixo risco de se tornarem inadimplentes) e ao monitoramento contínuo dos pagamentos das parcelas dos empréstimos, principalmente quando estes tomadores são empreendedores de baixa renda sem garantias reais. Estes problemas, identificados na literatura como de seleção adversa e risco moral, podem inviabilizar a expansão do serviço de crédito à grande parcela da população que acaba excluída do sistema financeiro. A atividade de microcrédito, apresentando respostas a problemas desta natureza, re-inserem a população de baixa renda no mercado de crédito. Estas atividades passam então a ser consideradas instrumentos de política pública ou desenvolvimento social e econômico local, com este propósito, merecendo estudos com relação à sua eficácia.

Desta forma, o objetivo deste artigo é proceder a uma avaliação comparativa da atividade de microcrédito entre Brasil e Bolívia. Esta avaliação se fará a partir da proposição e aplicação de um indicador capaz de sistematizar o cotejamento das principais iniciativas de cada país e seus respectivos arcabouços institucionais. A justificativa para escolha dos dois países pauta-se nos avanços alcançados pela atividade 
de microcrédito boliviana, país latino americano tido pela literatura internacional como mais bem sucedido no desenvolvimento desta atividade na região. Ressalte-se também o pioneirismo boliviano ao estabelecer um banco estritamente comercial voltado exclusivamente para serviços de microcrédito, modelo de expansão da atividade que vem sendo perseguido em outros países, inclusive o Brasil. O cotejamento desta experiência com a brasileira torna-se então particularmente interessante, servindo como referência e subsidiando o crescente interesse que a atividade de microcrédito vem despertando na concepção de políticas públicas e estratégias de agentes do mercado financeiro no país nas últimas duas décadas.

\section{Critérios de avaliação}

Um programa de microcrédito caracteriza-se pela estrutura estabelecida para a operacionalização e desenvolvimento das atividades de microcrédito. Fundamentado em estudos do Banco Mundial, do PREALC (Programa Regional de Emprego para América Latina e Caribe da OIT) e práticas de alguns dos principais apoiadores destes programas $^{2}$, estrutura-se fundamentalmente da articulação entre: a) foco do programa; b) forma de composição do fundo; c) combinação de instrumentos adequados à prestação de serviços de microcrédito; d) estratégias de sustentabilidade e; e) estratégias de expansão. Sua avaliação é fundamental para entendimento se de fato insere no mercado de crédito parcelas da população antes dele excluídas, além de revelar a capacidade de massificação destes instrumentos, em conformidade à capacidade destes programas ou atividades oferecerem respostas aos problemas relacionados à assimetria de informação no mercado de crédito já relacionados no capítulo anterior. Estes cinco critérios serão tratados amiúde nesta seção.

a) foco: Entende-se por foco qual categoria sócio-econômica da população está sendo beneficiada pelo programa de microcrédito. Interessa saber como os programas de microcrédito garantem o atendimento às parcelas da população realmente excluídas do setor financeiro convencional (em seguida, ao tratar do item sustentabilidade, serão

\footnotetext{
${ }^{2}$ Os principais estudos do Banco Mundial referem-se a Ledgerwood, 1999 e Schoenberg, 2000; do PREALC referem-se a Fuenzalida, 1990; Klein, 1990 e Mezzera 1993; os principais apoiadores dos programas referem-se a Accíon Internacional, UNICEF, GTZ, USAID, PACT.
} 
detalhadas quais condições permitem os programas a manutenção deste foco, relacionando-a com sua sustentabilidade financeira, a partir de uma troca).

A garantia de atendimento de uma parcela bem definida da população pode ser atingida a partir de estabelecimento de critérios de seleção da população favorecida, priorizando indicadores sociais ${ }^{3}$. Outros programas limitam o montante máximo de empréstimo, visando atingir apenas os pequenos empreendedores que fazem parte da população de baixa renda, sob o argumento de que limitando o valor máximo do empréstimo a um patamar baixo, estariam privilegiando empreendedores com pequenos negócios (nestes casos, o valor médio de empréstimos poderia ser utilizado como uma proxy para se avaliar a categoria de renda que se enquadraria o tomador) ${ }^{4}$.

A questão da focalização é latente principalmente nos programas públicos de microcrédito. Interessa definir o foco do programa, determinado se este instrumento será associado a uma política de geração de emprego e renda ou uma política de combate à pobreza. As políticas orientadas para o combate à pobreza abeiram-se às políticas de emprego, particularmente no seu componente geração de trabalho e renda. Esta imbricação deve-se ao entendimento de que uma das formas de se erradicar a pobreza é o apoio às atividades informais praticadas por indivíduos que se encontram abaixo da linha de pobreza ${ }^{5}$. Há dois possíveis agrupamentos para os indivíduos que se encontram sob a linha de pobreza: o primeiro reuniria aqueles que não exercem atividade econômica alguma, o segundo aqueles que exercem pequenas atividades econômicas (Garson, 1998).

O primeiro grupo necessitaria assistência diretamente voltada para sua sobrevivência enquanto o segundo não necessitaria assistência para eles próprios, mas para os empreendimentos que lhes garantem renda. Esta segmentação é particularmente interessante, pois permitem às políticas públicas de emprego e de combate à pobreza desenvolver instrumentos adequados para cada necessidade (como, por exemplo, medidas de garantia de renda mínima para indivíduos pertencentes ao primeiro grupo e

\footnotetext{
${ }^{3}$ Como programa que utiliza critérios desta natureza, pode ser citado o BRAC de Bangladesh, que se vale dos seguintes critérios: a) famílias chefiadas por mulheres; b) proprietários de terra com menos da metade de um acre; c) que possuam renda menor de US\$6.00 por mês (Passos, Paiva e Constanzi, 2001).

${ }^{4}$ Ver o foco das principais organizações de microcrédito em Microbanking Bulletin, 1998.

${ }^{5}$ Por pobreza se caracterizada a condição de renda insuficiente para a reprodução adequada do ser humano. A linha da pobreza é um recurso metodológico utilizado para se estimar a quantidade de famílias ou individuos que se encontram em condições de pobreza ou indigência. É definida como um determinado patamar de faixa de renda que permitiria às famílias ou indivíduos que disponibilizassem
} 
disponibilização de assistência técnica e crédito popular para o segundo) ${ }^{6}$. Desta forma, os programas de microcrédito se apresentam como serviços adequados apenas à restrita parcela da população que se encontra sob a linha de pobreza, o referido foco do microcrédito.

b) composição do fundo: As organizações de microcrédito operam a partir da disponibilização de recursos reunidos em um fundo financeiro destinado para a concessão de crédito, sua carteira de empréstimos. Interessa avaliar quão diversificada é origem deste fundo (assim como em que condições foi alocado para as organizações de microcrédito), e como a regulamentação do microcrédito vigente permite sua expansão ${ }^{7}$. O fundo pode ser originário de fontes diversas, provenientes de órgão de fomento internacionais, dos governos ou do próprio sistema financeiro. São montantes destinados a fundo perdido, oriundos de doações, emprestados às organizações de microcrédito em condições contratuais especiais ou não de mercado, além de captados juntos à própria clientela do microcrédito através de poupanças. Nos últimos dois casos, as condições de captação do fundo irão determinar, por sua vez, quais outras a entidade poderá oferecer ao tomador final do crédito. Desta forma, as organizações de microcrédito apresentam-se como intermediárias financeiras entre credores em última instância (proprietários dos recursos disponibilizados no fundo) e os tomadores finais (a população excluída do sistema financeiro), assumindo as seguintes funções: reduzir os custos da transação provenientes dos problemas de assimetria de informação, conforme analisado no capítulo anterior, e avalizar tomadores finais perante o proprietário dos fundos.

A regulamentação do microcrédito, item discutido no arcabouço institucional desta atividade, será fundamental para definir quais as alternativas de captação de recursos cabe a um programa. Desta forma, as ONGs não podem captar recursos em forma de poupança, por não serem estas organizações regulamentadas pela legislação financeira dos países, prerrogativa passível aos bancos comerciais, por outro lado. As legislações especificarão também quais formatos de programas de microcrédito poderão

rendimentos a partir deste nível, obtenção de bens e serviços capazes de suprir suas necessidades essenciais (Rima, 1996).

${ }^{6}$ Em 1981, relatório do Reserve Bank da Índia propôs a seguinte classificação de pobreza: a) aqueles que necessitam apenas de instrumentos de acesso ao crédito para dinamizar sua atividade econômica e lhes permitir transpor a linha de pobreza; b) aqueles que necessitam de instrumentos de acesso ao crédito e capital subsidiado para seu desenvolvimento e; c) aqueles para os quais crédito e capital não lhes seria solução para pobreza, requerendo assistência direta e subsídios de bem-estar social (Garson, 1998). 
captar investimentos externos e internos, e quais poderão se valer de doações. Diversificar as fontes de captação de recursos para composição dos fundos é imperativo para a garantia da expansão da clientela atendida pelos programas, impactando também na estratégia de auto-sustentabilidade das organizações.

c) combinação de instrumentos: Os principais instrumentos de microcrédito diferenciam estes serviços dos utilizados pelas intermediárias de crédito convencionais, apresentando soluções para alguns problemas relacionados com a assimetria de informação subjacente ao mercado de crédito. Interessa neste tópico avaliar se de fato o programa de microcrédito se vale de uma combinação de instrumentos capaz de cumprir seus objetivos (quer em relação à focalização, à auto-sustentabilidade ou à massificação) Os programas de microcrédito diferenciam-se por combinar de distintas formas os instrumentos característicos desta atividade, conforme os objetivos ou foco que pretendam atingir. Discute-se também se os serviços de microcrédito deveriam ou não disponibilizar demais serviços de apoio ao pequeno empreendedor, além do crédito.

A delimitação das atividades da organização de microcrédito pauta-se em argumentos de duas correntes de pensamento. A primeira, denominada desenvolvimentista, defende que os esforços dos programas de microcrédito devam estar voltados em prol do combate à problemática estrutural da pobreza. Desta forma, entende a organização de microcrédito como um agente de desenvolvimento social, devendo a entidade que conceda o crédito também disponibilizar outras formas de apoio ao pequeno empreendedor, sem as quais não haveria como romper a linha de pobreza sob a qual este se encontra (como capacitação técnico-gerencial, suporte à comercialização, experiências de vida comunitária, entre outras). A segunda, denominada minimalista, entende que um instrumento de acesso ao crédito só pode cumprir sua função se atingir a sustentabilidade. Esta condição se justificaria, pois sem ela o serviço estaria fadado à descapitalização, deixando de atingir seus objetivos ${ }^{8}$ (Mezzera, 1993).

\footnotetext{
7 A importância de diversificação do fundo de microcrédito e sua relação com a regulamentação da atividade, podem ser aprofundados em Ledgerwood, 1999.

${ }^{8}$ Para se tornar sustentável seria necessário reduzir os custos administrativos da organização de microcrédito e seguir exclusivamente parâmetros financeiros do mercado, o que impediria a entidade de oferecer outras atividades complementares de apoio ao pequeno empreendedor (Ledgerwood, 1999),
} 
d) sustentabilidade: Aliviar a pobreza através de provisão de crédito subsidiado fez parte da estratégia do governo de muitos países nas últimas décadas ${ }^{9}$. Entretanto, poucas foram bem sucedidas, apresentando altas taxas de inadimplência, rápida descapitalização dos fundos, desvios de objetivo/foco e barreiras à massificação. $\mathrm{O}$ subsídio visa tornar as taxas de juros dos programas menores, justificando-se pelo fato de os pequenos investidores não suportarem taxas elevadas (garantindo assim que muitos projetos de investimento viáveis possam ser executados). O argumento é rebatido a partir da constatação que os pequenos empreendedores acabam recorrendo a agiotas, na falta de alternativa creditícia, que cobram taxa de juros muito maiores ${ }^{10}$. $\mathrm{O}$ efeito final do subsídio (e do assistencialismo) é a rápida corrosão da dotação orçamentária destinada aos programas de microcrédito, e o desestímulo ao desenvolvimento de programas privados de microcrédito (lucrativos ou não), incapazes de concorrer com taxas de juros subsidiadas. De qualquer forma, mesmo os programas privados de microcrédito apresentam dificuldades de atingir auto-sustentabilidade, sendo não raramente subsidiados por fundos públicos e privados ${ }^{11}$.

Nas últimas décadas, atingir a auto-sustentabilidade passa a ser considerado um critério de desempenho fundamental nos programas de microcrédito, privados ou públicos. As possíveis formas de cálculo da taxa de juros dos programas está no cerne desta questão. Conceitualmente, cunham-se dois extremos entendimentos de como deve a entidade calcular suas taxas de juros: de forma filantrópica, ou estritamente financista. No primeiro caso, defende-se que a organização de microcrédito deve se valer de uma taxa de juros igual a zero, por ter propósitos unicamente sociais (será uma abordagem possível, principalmente quando o fundo disponibilizado para esta entidade realizar seus empréstimos for oriundo de doações). Na outra ponta, defende-se que a taxa de juros cobrada pela organização de microcrédito deve ser igual àquela vigente no mercado, o

\footnotetext{
${ }^{9}$ Muitos programas de microcrédito continuam sendo subsidiados diretamente através de doações e indiretamente, a partir de termos contratuais menos exigentes. Entretanto, é comum que os programas de menor sustentabilidade sejam aqueles que mais se desviem dos propósitos do microcrédito servir à população de baixa renda (Morduch, 1999).

${ }^{10}$ Esta discussão pode ser aprofundada, a partir de Morduch, 1999 e Schoenberg, 2000.

${ }^{11}$ Esta constatação ocorre mesmo em experiências sofisticadas de microfinanças, que atrelam aos serviços de crédito serviços de poupança. Uma possível explicação para que estas organizações não se autosustentem é que a poupança gerada pela população de baixa renda é significantemente menor que os recursos necessitados para investimento em pequenos empreendimentos por esta mesma população. Para maior aprofundamento nesta discussão, ver Ledgerwood, 1999, e Morduch, 1999. Para resultados de desempenho relacionados à auto-sustentabilidade das principais experiências de microcrédito, ver Microbanking Bulletin, 1998.
} 
que evitaria distorções financeiras e cultivaria nos tomadores cultura de tratar seus empreendimentos de forma mais diligente.

Na prática, é mais comum observar-se organizações de microcrédito que atuam em zonas intermediárias destas posições extremas, possibilitando acesso ao crédito com taxas de juros parcialmente subsidiadas ${ }^{12}$. As recomendações e práticas convergem, no entanto, para o entendimento que a taxa de juros dessas entidades deva cumprir as seguintes condições: a) cobrir o custo de oportunidade dos recursos disponibilizados para a entidade através de fundos; b) cobrir custos operacionais da entidade, buscando sustentabilidade da instituição e; c) possibilitar que esta amplie sua carteira, aumentando a abrangência de sua atuação. Ou seja: taxa de juros da organização de microcrédito = custo de oportunidade de fundos de crédito disponíveis + ao menos uma parcela dos custos operacionais da entidade + margem que propicie o crescimento da instituição creditícia. É interessante notar que este cálculo não raramente acarreta taxas de juros cobradas pela organização de microcrédito maiores que aquelas observadas no mercado. IAinda assim atraentes para o tomador, pois sua alternativa é aquela oferecida pelo agiota, o que equivale a uma taxa de juros extremamente alta, ou nenhuma outra (Ledgerwood, 1999).

Assim, a troca entre manutenção do foco dos programas e a garantia de sustentabilidade passa a ser questão fundamental para o estabelecimento de um programa de microcrédito. A garantia do foco não é o único propósito de um programa desta natureza, com o risco de reprodução de programas de combate à pobreza totalmente subsidiados. A garantia de manutenção do foco vis a vis a busca de autosustentabilidade (ainda que nem sempre seja possível de ser atingida) são indissociáveis aos programas de microcrédito. Desta forma, os propósitos dos programas de microcrédito são entendidos de forma dual, atentos concomitantemente à focalização de determinada população-alvo e à sustentabilidade dos programas ${ }^{13}$.

e) massificação: Finalmente, um dos mais latentes problemas dos programas de microcrédito é sua escassa cobertura em relação ao universo de potenciais usuários. Interessa então reconhecer qual a capacidade de expansão dos programas de microcrédito para atender sua clientela potencial e, sobretudo, quais as barreiras que os

\footnotetext{
12 Diferentes abordagens com relação à auto-sustentabilidade das principais organizações de microcrédito podem ser encontradas em Microbanking Bulletin, 1998.

${ }_{13}$ Para aprofundamento da discussão do foco dos programas de microcrédito e sua relação com a sustentabilidade dos programas ver Garson, 1998.
} 
impedem de se expandir. São os principais fatores que impediriam a massificação desses programas ${ }^{14}$ : i) resistência das intermediárias financeiras formais em adotar instrumentos de microcrédito que reduzam seus problemas de assimetria de informação, com persistente desconfiança da capacidade de sobrevivência e solvência dos pequenos empreendimentos, acrescida da crença que o desenvolvimento econômico per se resolveria a recobo os problemas do setor informal; ii) cultura assistencialista - o corpo dirigente e técnico dos programas públicos de desenvolvimento econômico não consideram o setor informal como alvo de seu campo de atuação, encarregando os organismos de assistência social de atendê-lo, que tendem a optar por programas de crédito subsidiados; iii) ausência de regulamentação condizente à expansão do microcrédito; iv) setor financeiro incipiente, sendo que grande parte dos países em desenvolvimento onde se desenvolvem os programas de microcrédito possuem mercados financeiros incipientes, o que se constitui um impedimento de massificação dos programas via atrelamento ao setor financeiro convencional; v) receios de que concorrência no mercado de microcrédito aumentaria o risco das carteiras compostas com fundos destinados a este setor, considerando que um investidor poderia contrair empréstimos em várias organizações ao mesmo tempo, apenas rolando seu endividamento.

Por fim, cabe destacar outros fatores impeditivos para a massificação dos programas de microcrédito estariam relacionados com o impacto destes programas sobre sua clientela (oriunda em grande parte do setor informal da economia: i) exigência de programas educativos/técnicos/administrativos complementares, sem os quais empreendimentos tomadores de microcrédito tenderiam ao fracasso (este componente representaria um custo adicional elevado em caso de os programas se tornarem massivos); ii) falta de capacidade do mercado absorver o crescimento do setor informal (provocando impactos pífios sobre a geração de emprego e renda); iii) inexistência de avaliações rigorosas e comparativas de resultados dos programas vigentes que permitiriam respaldar a formulação de programas mais ambiciosos (Fuenzalida, 1993; Mezzera, 1993; Garson, 1998).

\footnotetext{
${ }^{14}$ A síntese destes problemas, e sua relação com a incapacidade de cobertura do potencial de clientes de microcrédito, pode ser aprofundada em Fuenzalida, 1993; Garson, 1998; Ledgerwood, 1999 e Morduch, 1999.
} 


\section{Programas de Microcrédito selecionados}

Identificam-se três formatos de programas típicos em cada um dos países, Brasil e Bolívia. Para cada um destes foi selecionado o principal representante, conforme critérios de número de clientes e tamanho da carteira. Os três principais formatos de programas brasileiros (e respectivos programas de microcrédito representantes), são: a) ONG (neste caso, selecionou-se a rede de ONGs FENAPE, que congrega os CEAPEs); b) banco comercial (mesmo que operado por um banco público; programa CrediAmigo); c) organização de controle misto (ou ONG mista, Portosol). Analogamente, são os programas bolivianos selecionados: a) ONG (Prodem); b) banco comercial (Bancosol) e; c) FFP (Caja Los Andes).

Os três principais formatos brasileiros (banco comercial/público, ONG e ONG mista) detêm $88 \%$ da carteira de microcrédito brasileira e atendem $97 \%$ dos clientes ativos (considerando-se os programas com mais de 2.000 clientes ativos). Não se considera nesta análise, portanto, a experiência governamental do Banco do Povo de SP, devido a completa ausência de programa boliviano similar. Quanto à Bolívia, os formatos tratados correspondem aos únicos que operam atividade de microcrédito.

A seguir, para cada um destes programas serão introduzidas informações sistematizadas relacionadas a: composição de seus fundos; características e indicadores relacionados aos instrumentos de crédito utilizados; indicadores que permitem inferências com relação ao foco dos programas; indicadores relacionados à sustentabilidade e; tamanho da clientela ativa destes programas ${ }^{15}$.

\footnotetext{
15 Todas as informações correspondem a julho de 1999, tendo sido organizadas a partir de entrevistas e pesquisas em fontes secundárias, como Goldmark, 2000; Schoenberg, 2000 e Funda-Pró 1999. Para o período, foi utilizado taxa de conversão US\$1.00 igual a R $\$ 1,79$.
} 
Quadro (3.1) Programas Brasileiros

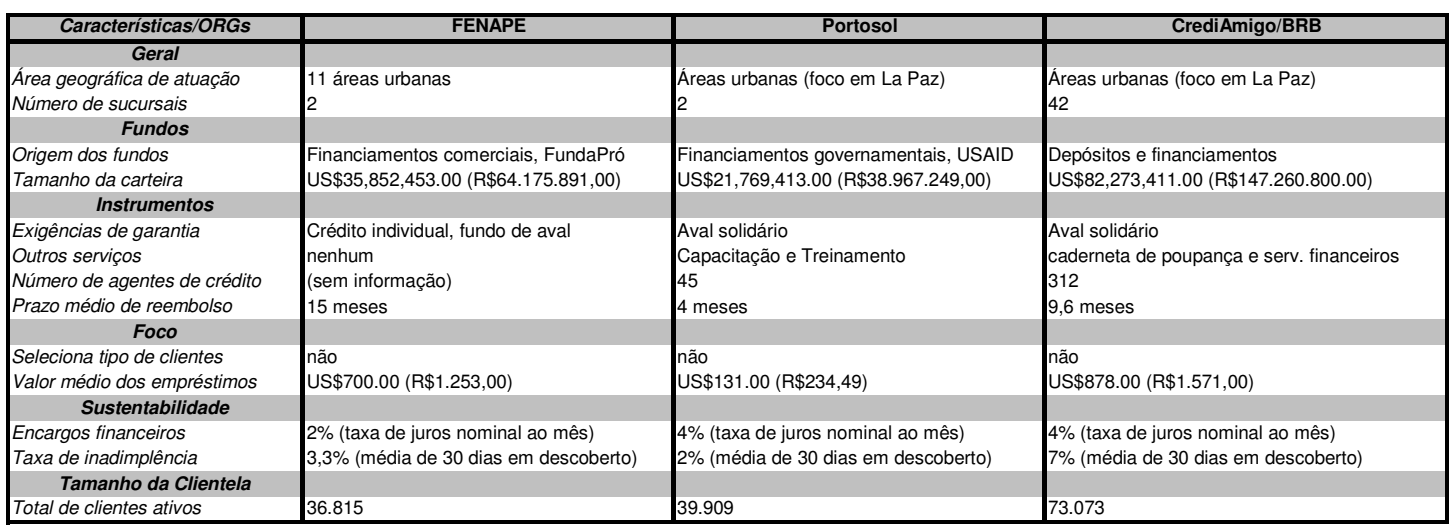

Quadro (3.2) Programas Bolivianos

\begin{tabular}{|c|c|c|c|}
\hline Características/ORGs & Bancosol & PRODEM & Caja Los Andes \\
\hline \multicolumn{4}{|l|}{ Geral } \\
\hline \multicolumn{4}{|l|}{ Fundos } \\
\hline $\begin{array}{l}\text { Exigências de garantia } \\
\text { Outros serviços } \\
\text { Número de agentes de crédito } \\
\text { Prazo médio de reembolso }\end{array}$ & $\begin{array}{l}\text { Aval solidário } \\
\text { nenhum } \\
213 \\
3 \text { meses }\end{array}$ & $\begin{array}{l}\text { Consignação, fiadores e aval solidário } \\
\text { Capacitação } \\
14 \\
6 \text { meses }\end{array}$ & $\begin{array}{l}\text { Consignação ou aval solidário } \\
\text { Capacitação } \\
75 \\
6 \text { meses }\end{array}$ \\
\hline \multicolumn{4}{|l|}{ Foco } \\
\hline $\begin{array}{l}\text { Seleciona tipo de clientes } \\
\text { Valor médio dos empréstimos }\end{array}$ & $\begin{array}{l}\text { não } \\
\text { US\$241.00 (R\$431,39) }\end{array}$ & $\begin{array}{l}\text { não } \\
\text { US } \$ 660.00(R \$ 1.181,00)\end{array}$ & $\begin{array}{l}\text { não } \\
\text { US\$314.00 (R\$562,06) }\end{array}$ \\
\hline \multicolumn{4}{|l|}{ Sustentabilidade } \\
\hline $\begin{array}{l}\text { Encargos financeiros } \\
\text { Taxa de inadimplência }\end{array}$ & $\begin{array}{l}5 \% \text { (taxa de juros nominal ao mês) } \\
4 \% \text { (média de } 30 \text { dias em descoberto) }\end{array}$ & $\begin{array}{l}3,5 \% \text { (taxa de juros nominal ao mês) } \\
3,7 \% \text { (média de } 30 \text { dias em descoberto) }\end{array}$ & $\begin{array}{l}5,5 \% \text { (taxa de juros nominal ao mês) } \\
4 \% \text { (média de } 30 \text { dias em descoberto) }\end{array}$ \\
\hline
\end{tabular}

\section{Avaliação comparativa do microcrédito no Brasil e Bolívia}

O objetivo deste último capítulo é aplicar os critérios de avaliação do microcrédito apresentados, valendo-se das informações de programas selecionados para Brasil e Bolívia, gerando um indicador de eficácia que possibilite a avaliação comparativa entre as atividades dos dois países. A metodologia que orientará a construção do indicador de eficácia é apresentada na seção 4.1. Para cada diferente formato de programa identificado em ambos países, através do estudo de seu principal representante, serão então discutidos: foco, composição do fundo, combinação de instrumentos, sustentabilidade e massificação (seção 4.2). Almeja-se a avaliação comparativa da atividade de microcrédito entre Brasil e Bolívia através de um indicador síntese, fundamentado na análise desta seleção de programas, subordinados aos respectivos arcabouços institucionais (seção 4.3). 


\subsection{Metodologia}

O desenvolvimento de indicadores sociais visa suprir com informações sistematizadas os poderes públicos e a sociedade civil, de forma geral, subsidiando sua capacidade de analisar a evolução da qualidade de vida das populações, em particular revelando a eficácia de determinados programas, projetos ou ações voltados para mesmo propósito. Os esforços direcionados para mensurar quantitativa ou qualitativamente questões concernentes ao aumento do bem-estar da população (saúde, educação, emprego, entre outras), tornam-se cada vez mais importantes como orientadores das decisões de investimento público e privado, tanto quanto indicadores de crescimento econômico ou financeiro. Entretanto, o acompanhamento da qualidade de vida, ou desenvolvimento sócio-econômico, das populações gera desafios metodológicos associados a conceitos ainda bastante diversos a respeito de como tratar sua eficácia ou eficiência ${ }^{16}$.

Desta forma, a partir do desenvolvimento teórico apresentado (Capítulo II), serão avaliadas comparativamente as atividades de microcrédito do Brasil e Bolívia, segundo critérios estabelecidos: foco, composição do fundo, combinação de instrumentos, sustentabilidade e massificação. Em cada critério serão identificados parâmetros de eficácia condizentes com as respostas do microcrédito para os principais problemas oriundos da assimetria da informação no mercado de crédito que exclui grande parcela da população deste mercado, principalmente a população de baixa renda. Estes parâmetros assumirão valores ordinais conforme a capacidade de cada programa oferecer resposta aos problemas de assimetria de informação, relacionando também as características e desempenho dos programas analisados aos arcabouços institucionais que os envolvem. Objetiva-se a construção de um indicador de eficácia que possa sistematizar uma avaliação comparativa entre as atividades de microcrédito destes países.

A construção do indicador será propiciada pela ordenação dos programas de microcrédito selecionados (três de cada país), conforme apresentem características operacionais com maior ou menor aderência aos instrumentos típicos de microcrédito, além de melhor ou pior desempenho. Desta forma, atribuir-se-á (1) para o programa mais eficaz, (2) para o segundo, e assim por diante. Em caso de programas adotarem 
características operacionais ou de desempenho análogos, ou não havendo fundamento para considerá-los menos os mais eficazes em determinado parâmetro, as experiências recebem a mesma ordenação. As ordenações serão trabalhadas em cada parâmetro que compõe o respectivo critério de avaliação. Em seguida, para cada um dos cinco critérios de avaliação analisados, os programas somarão um índice de ordenação (soma linear da ordenação obtida em cada parâmetro que os compõem), gerando indicadores intermediários.

A construção do indicador de eficácia que permitirá uma sistematização da avaliação comparativa entre ambos países obedecerá ao seguinte procedimento: a) soma linear dos indicadores intermediários obtidos por cada programa em cada um dos cinco critérios de avaliação; b) agrupamento dos programas de cada país, somando-se seus respectivos indicadores intermediários, gerando um somatório único por país, revelando a atividade de microcrédito mais eficaz a partir do menor valor obtido.

\subsection{Construção dos Indicadores Intermediários}

a) foco: Parâmetros de eficácia que permitem avaliar a focalização dos programas de microcrédito são: i) estabelecimento ou não de critérios de seleção da população-alvo (rendimento familiar, posses, gênero, etc.); ii) valor médio de empréstimos concedidos pelos programas. Com relação ao segundo, cabe frisar que os programas de microcrédito tratados não disponibilizam informações sócio-econômicas de seus tomadores, o que inviabiliza um estudo comparativo aprofundado das características de cada população-alvo e que poderia fornecer informação mais apurada se os contemplados pelos programas são de fato os excluídos do mercado de crédito formal. Uma proxy comumente utilizada para se induzir a condição econômica dos tomadores é o valor de empréstimo médio contraído ${ }^{17}$. Este indicador é interessante, sobretudo como indicativo se estes valores médios estão abaixo do piso de empréstimos praticado pelo sistema financeiro convencional. Posto que grande parte dos programas de microcrédito estabelece valores máximos de empréstimos, o valor médio destes

\footnotetext{
${ }^{16}$ Para uma discussão sobre indicadores sociais e desenvolvimento sócio-econômico, ver Banco Mundial, 1997.

${ }^{17}$ Argumentos justificando a proxy valor médio dos empréstimos para tratar a categoria sócio-econômica dos tomadores podem ser encontrados em Ledgerwood, 1999, e Morduch, 1999.
} 
poderá sugerir também qual o tamanho do empreendimento tomador, e por extensão a situação econômica do empreendedor.

Quanto ao estabelecimento ou não de critérios de seleção da população-alvo, nenhum dos programas selecionados (para Brasil e Bolívia) adota pré-requisitos com esta finalidade. Os programas apenas definem genericamente sua população-alvo, sem impor restrições relacionadas a indicadores sócio-econômicos. De forma genérica, estabelecem que seus tomadores são aqueles responsáveis por empreendimentos de pequeno porte, formalizado ou não ${ }^{18}$. A única condição que aparece na maioria dos programas é a necessidade de o empreendedor possuir experiência (de 6 meses a 1 ano) na atividade econômica para a qual demanda crédito, o que não constitui, em verdade, uma pré-requisito sócio-econômico. Os programas brasileiros e bolivianos selecionados também não estabelecem restrições relacionadas a gênero do tomador ${ }^{19}$.

Os programas de microcrédito brasileiros estabelecem valores máximos de empréstimos bastante diferenciados. Enquanto o CrediAmigo estabelece um teto de R \$700,00 (US\$391.00), em média, os CEAPEs que compõem a rede FENAPE fixa um teto de R \$5.000,00 (US\$2,793.00), e o Portosol um teto de RS15.000,00 $(\mathrm{US} \$ 8,379.00)^{20}$. No caso dos programas bolivianos, para o Bancosol o mínimo do empréstimo individual é US5,000.00 (para o grupo solidário, o empréstimo máximo é de US\$20,000.00) ${ }^{21}$; para o Prodem, o teto para o primeiro empréstimo já é bem menor, em torno de US\$100.00, montante máximo de empréstimo individual ${ }^{22}$. Os FFPs, diferentemente dos dois programas anteriormente apresentados, possuem restrições legais estabelecendo que o valor máximo de empréstimo concedido, não poderá ultrapassar $1 \%$ de seu capital. Desta forma, a Caja Los Andes, submetida à legislação dos FFPs, não especifica um teto máximo de empréstimos, estudado em cada caso.

\footnotetext{
${ }^{18}$ Exceção seja feita ao programa boliviano Caja Los Andes, que especifica tomadores de microcrédito poderão também ser compostos por médias empresas (Funda-Pró, 1999).

${ }^{19}$ Os programas bolivianos (principalmente Bancosol e Prodem apresentam cerca de $70 \%$ de tomadores de gênero feminino, enquanto que os brasileiros apresentam uma distribuição média de $50 \%$ entre os gêneros (Schoenberg, 2000). Estas distribuições não estão relacionadas, entretanto, a qualquer prérequisito que oriente os programas a pré-estabelecer proporções para gênero.

${ }^{20}$ Estas informações foram colhidas diretamente junto às organizações de microcrédito, para fins do ano de 1999, à taxa de câmbio R \$1,00 igual a US\$1.79.

${ }^{21}$ Para maiores informações relacionadas ao foco do Bancosol e Prodem, ver Fidler, 1998.

22 É importante frisar que para os casos bolivianos, assim como os brasileiros, as informações apresentadas correspondem ao teto do primeiro empréstimo solicitado. Como grande parte dos programas utilizam o instrumento de crédito sucessivo, em um segundo empréstimo estes tetos tendem a ser maiores. As informações bolivianas apresentadas foram colhidas junto a Asofin, 2000.
} 
O indicador valor médio dos empréstimos observados nos programas selecionados permite cotejar se, em média, os empréstimos estão indo para empreendimentos menores ou maiores, valendo-se como proxy de tamanho do empreendimento, o tamanho de empréstimo requerido/concedido. Nos programas brasileiros nota-se que o valor médio dos empréstimos é menor que nos representantes bolivianos selecionados. Segundo quadros apresentados anteriormente (Capítulo IV), o menor empréstimo médio é observado no CrediAmigo, correspondendo a $\mathrm{R} \$ 431,39$ (US\$241.00) (coerente com o menor teto de crédito de todos os programas), seguido pelo valor médio observado nas integrantes da FENAPE, de R\$562,06 (US\$314.00), e do Portosol, de R \$1.181,00 (US\$660.00). Na Bolívia, em contraponto, com exceção ao baixo valor médio do Prodem de US\$131.00, observa-se valores médios mais elevados para o Bancosol, de US\$878.00, e da Caja Los Andes, de US\$700.00.

Ainda que estes últimos estejam associados a uma estratégia de sustentabilidade financeira, é fato que os programas mais integrados ao sistema financeiro boliviano acabem contemplando empreendimentos um pouco maiores que os contemplados por uma organização fora do sistema financeiro (como o Prodem), correndo maior risco de se afastar de seu foco ${ }^{23}$. No caso brasileiro, interessante notar que o maior índice de valor médio de empréstimos seja observado em uma ONG mista, e não em uma instituição atrelada ao sistema financeiro (utilizando o mesmo argumento dos programas financeirizados bolivianos). Este ponto permite colocar em dúvida se o CrediAmigo não tem sido em parte subsidiado através de repasses financeiros de outras áreas do $\mathrm{BNB}^{24}$.

Por fim, é apresentado um quadro síntese com informações dos programas brasileiros e bolivianos, com relação às duas variáveis desenvolvidas para caracterizar o foco dos programas (com relação ao segundo, os programas foram agrupados por quartil, estabelecidos a partir do maior e menor índice de valor médio):

\footnotetext{
${ }^{23}$ Há que se atentar também que a tendência de crescimento da taxa média de empréstimo (observada principalmente no Bancosol), é um indicador que os tomadores estabilizam sua capacidade de pagamento e passam a demandar empréstimos maiores. De qualquer forma, sub-existe o risco de o programa de microcrédito se afastar de seu foco inicial se acompanhar exclusivamente os tomadores que progridem (Schoenberg, 2000).

${ }^{24}$ Esta discussão pode ser aprofundada em Schoenberg, 2000.
} 
Quadro (4.1) - Foco dos Programas - Parâmetros

\begin{tabular}{|c|l|}
\hline \multicolumn{1}{|c|}{ FOCO } & \multicolumn{1}{c|}{ Programas } \\
\hline Critério de Seleção do Tomador & \\
\hline estabelece & \\
\hline não estabelece & $\begin{array}{l}\text { FENAPE, CrediAmigo, Portosol } \\
\text { Bancosol, PRODEM, Caja Los Andes }\end{array}$ \\
\hline Volume Médio de Empréstimos & \\
\hline 1o. Quartil (até US\$252.25) & PRODEM, CrediAmigo \\
\hline 2o. Quartil (até US\$504.50) & FENAPE \\
\hline 3o. Quartil (até US\$756.75) & Portosol, Caja Los Andes \\
\hline 4o. Quartil (até US\$1,009.00) & Bancosol \\
\hline
\end{tabular}

b) composição dos fundos: Para este critério de avaliação serão tratados os seguintes parâmetros de eficácia: i) tamanho da carteira dos programas de microcrédito selecionados; ii) capacidade de diversificação e expansão da carteira, segundo prerrogativas garantidas pela legislação vigente (doações, financiamentos $e$ poupança). O segundo item, particularmente relaciona-se ao arcabouço institucional em que estão inseridas as organizações de microcrédito.

Com relação ao tamanho da carteira, observa-se que os programas bolivianos selecionados apresentam montantes disponíveis para empréstimos bem maiores que os brasileiros, independentemente do formado da organização (conforme Capítulo IV). Assim, mesmo a Prodem sendo uma ONG que iniciou atividades no mesmo período da FENAPE (através do CEAPE/PE em 1987), apresenta carteira disponibilizando cerca de US\$21,7 milhões de dólares contra US\$7,3 do programa brasileiro. Analogamente, o banco comercial boliviano Bancosol tem carteira muito superior à experiência brasileira de integração do microcrédito ao sistema financeiro convencional, o CrediAmigo (US\$82,2 milhões de dólares contra US\$4,9). O FFP Caja Los Andes é a segunda maior carteira boliviana (US\$35,8 milhões de dólares), apesar de seu pouco tempo de existência (5 anos). O Portosol, ONG mista praticamente com a mesma idade da Caja Los Andes apresenta uma carteira de US\$1,7 milhão de dólares.

Estudo do Banco Mundial analisa as características e o desempenho de organizações de microcrédito do Brasil, de onde se extraem os seguintes pontos comuns para o caso particular dessas três programas selecionados ${ }^{25}$ : a) seus fundos são constituídos a partir da própria participação dos acionistas, baseados em doações, ou a partir de empréstimos de longo prazo com taxas de juros baixas (caracteristicamente subsidiados); b) os três programas recebem doações de instituições internacionais, para a estruturação de suas atividades beneficiando-se também de assistência técnica

\footnotetext{
${ }^{25}$ Conclusões a partir de Schoenberg, 2000.
} 
internacional, também sob forma de doações (Como Banco Mundial, GTZ, UNICEF, entre outros). Como principal financiador público dos programas de microcrédito Portosol e FENAPE, apresenta-se $\mathrm{PCPP}^{26}$. Neste caso, os recursos alocados em ambos programas recebem o tratamento de empréstimos, devendo ser restituídos ao BNDES mediante pagamento de acordada taxa de juros ${ }^{27}$. O CrediAmigo conta também com financiamento de outras linhas de crédito do BNB, não subsidiadas (é importante frisar que embora constitua-se um programa interno a uma instituição financeira convencional, o CrediAmigo não se vale de captação de poupança articulada com sua carteira de empréstimos).

Com relação aos programas bolivianos, a principal distinção dos brasileiros, fica por conta da existência de uma legislação da atividade de microcrédito mais condizente para a diversificação da captação de recursos (o Prodem apresenta restrições de captação bastante semelhantes as ONGs brasileiras, tendo seu fundo composto principalmente a partir de doações, como as provenientes da USAID). Assim, o Bancosol por se constituir como um banco comercial está autorizado e mantém também atividades de captação de poupança junto ao público, que garante importante fonte de alavancagem (em 1999, os recursos que compunham o fundo de empréstimos do Bancosol provenientes de poupança correspondiam a $25 \%$ do financiamento de sua carteira). Da mesma forma, os FFPs também podem se valer de serviços financeiros de captação de poupança, fundamentais para a expansão de programas como a Caja Los Andes (27,2\% do financiamento da carteira da Caja Los Andes correspondia a captação a partir de caderneta de poupança. Ambos formatos de instituições também são autorizadas pela legislação a fazer financiamentos nacionais e internacionais.

Por fim, é apresentado um quadro síntese com informações dos programas brasileiros e bolivianos, com relação aos dois parâmetros estabelecidos para caracterizar a composição de fundos dos programas (com relação ao primeiro, os programas foram agrupados por quartil, estabelecidos a partir do maior e menor valor da carteira):

\footnotetext{
${ }^{26} \mathrm{O}$ PCPP/BNDES têm se colocado como um dos principais financiadores das organizações civis de microcrédito, disponibilizando volume pouco maior que $\mathrm{R} \$ 16,2$ milhões de reais em seus 3 primeiros anos de atividade (correspondendo a mais de $30 \%$ da composição total das carteiras das organizações de microcrédito brasileiras), segundo Goldmark, 2000.

${ }^{27}$ Para detalhamento do PCPP/BNDES ver capítulo II; para aprofundamento nos critérios e condições do programa ver Azeredo, 1998, e Goldmark, 2000.
} 
Quadro (4.2) - Composição dos Fundos - Parâmetros

\begin{tabular}{|c|c|}
\hline COMPOSIÇĀO DO FUNDO & Programas \\
\hline \multicolumn{2}{|l|}{ Tamanho da Carteira } \\
\hline 10. Quartil (até US\$20,9 mi) & FENAPE, Portosol, CrediAmigo \\
\hline 2o. Quartil (até US\$41,9 mi) & Prodem, Caja Los Andes \\
\hline \multicolumn{2}{|l|}{ 3o. Quartil (até US\$69,9 mi) } \\
\hline 40. Quartil (até US\$83,9 mi) & Bancosol \\
\hline \multicolumn{2}{|l|}{ Formas de Captação } \\
\hline doações & FENAPE, Portosol, PRODEM \\
\hline doações, financiamento & CrediAmigo \\
\hline doações, financiamento e poupança & Bancosol, Caja Los Andes \\
\hline
\end{tabular}

c) combinação de instrumentos: A utilização de uma combinação de instrumentos de microcrédito é imprescindível para garantir os objetivos de um programa de microcrédito (seja os relacionados à focalização, auto-sustentabilidade ou expansão). Neste tópico serão analisados os seguintes parâmetros de eficácia: i) utilização de instrumentos de microcrédito combinados; ii) oferecimento de outros serviços de apoio ao empreendimento. Com relação ao primeiro, serão apreciados sete principais instrumentos utilizados pelos programas de microcrédito (aval solidário, monitoramento mútuo, incentivos progressivos, parcelamento do pagamento em períodos curtos, garantias alternativas, atuação em âmbito local e priorização de gênero, conforme apresentado no Capítulo I). Com relação ao segundo, serão considerados se os programas de microcrédito oferecem apenas serviços de crédito ou também outros de apoio técnico ao empreendimento.

O quadro que segue ilustra quais instrumentos de crédito são utilizados pelos programas brasileiros e bolivianos. O mesmo quadro irá consolidar o número de instrumentos utilizado por cada programa e indicar se o programa se vale de outros serviços de apoio técnico ao empreendimento ${ }^{28}$.

\footnotetext{
${ }^{28}$ O presente quadro foi montado a partir de informações contidas em Funda-Pró, 1999, Schoenberg, 2000 , além de entrevistas junto às organizações e consulta a material com respectivas metodologias de microcrédito.
} 
Quadro (4.3) - Combinação de Instrumentos - Parâmetros

\begin{tabular}{|l|c|c|c|c|c|c|}
\hline COMBINAÇÃO DE INSTRUMENTOS Organizações & \multicolumn{5}{l|}{} \\
\hline Instrumento de Microcrédito & FENAPE & Portosol & Crediamigo & Bancosol & PRODEM & Caja L. Andes \\
\hline aval solídário & $\mathbf{X}$ & $\mathbf{X}$ & $\mathbf{X}$ & $\mathbf{X}$ & $\mathbf{X}$ & \\
\hline monitoramento mútuo & $\mathbf{X}$ & $\mathbf{X}$ & $\mathbf{X}$ & $\mathbf{X}$ & $\mathbf{X}$ & $\mathbf{X}$ \\
\hline incentivos progressivos & $\mathbf{X}$ & $\mathbf{X}$ & $\mathbf{X}$ & $\mathbf{X}$ & $\mathbf{X}$ & $\mathbf{X}$ \\
\hline parcelamento do pagamento & $\mathbf{X}$ & $\mathbf{X}$ & $\mathbf{X}$ & & $\mathbf{X}$ & \\
\hline garantias alternativas & $\mathbf{X}$ & $\mathbf{X}$ & $\mathbf{X}$ & $\mathbf{X}$ & $\mathbf{X}$ & $\mathbf{X}$ \\
\hline âmbito local & $\mathbf{X}$ & $\mathbf{X}$ & & $\mathbf{X}$ & $\mathbf{X}$ & \\
\hline priorização de gênero & & & & $\mathbf{X}$ & $\mathbf{X}$ & \\
\hline total de instrumentos combinados & 6 & 6 & 5 & 6 & 6 & 3 \\
\hline outros serviços de apoio & sim & sim & sim & não & sim & não \\
\hline
\end{tabular}

O quadro apresentado demonstra que a maioria das organizações de microcrédito de ambos países se vale dos principais instrumentos propostos (exceção feita à Caja Los Andes que se vale de poucos instrumentos de microcrédito, dispensando mesmo o aval solidário, preferindo adotar um sistema de aval individual com garantias alternativas). Com relação ao âmbito local, destaque-se que embora FENAPE e Bancosol atuem em mais de uma região (FENAPE possui treze CEAPEs associados e o Bancosol atua com quatro escritórios), ambos programas focam um âmbito local em cada uma de suas área de atuação. Diferente do que ocorre com o programa CrediAmigo (um programa extensível a todos os estados da região nordeste brasileira) e com a Caja Los Andes (define genericamente 11 regiões de atuação). Por fim, cabe frisar que embora nenhum programa crie pré-requisitos para privilegiar o gênero feminino, este é muito mais contemplado nos programas do Bancosol e do Prodem (cerca de $70 \%$ dos tomadores), do que nos demais (que tem como clientela cerca de $50 \%$ do gênero).

d) sustentabilidade: A inexistência de uma metodologia única para construção de indicadores de sustentabilidade comuns entre os programas tratados, não permite um aprofundamento analítico financeiro dos programas selecionados ${ }^{29}$. Desta forma, serão considerados os seguintes parâmetros de eficácia: i) obtenção ou não de autosustentabilidade administrativa elou financeira dos programas (em contraponto a programas subsidiados); ii) controle da taxa de inadimplência, para que não comprometa a sustentabilidade dos programas. Com relação ao segundo, cabe frisar

\footnotetext{
${ }^{29}$ O estudo do Banco Mundial também constata que não é possível proceder análise financeira comparativa mais acurada entre os programas brasileiros e bolivianos, devido às diferentes práticas contábeis utilizadas (Schoenberg, 2000).
} 
que seu índice está intrinsecamente associado à utilização de instrumentos próprios do microcrédito, que apresentam soluções para o problema de risco moral.

A partir das informações sistematizadas anteriormente (Capítulo IV), tecem-se os seguintes comentários gerais: a) as taxas de juros cobradas pelos programas brasileiros são semelhantes àquelas praticadas por bancos e financiadoras brasileiros de empréstimos para pessoa física ${ }^{30}$; b) as taxas praticadas pelos programas brasileiros são consistentes com aquelas praticadas pelos programas bolivianos, embora maiores que aquelas praticadas pelas instituições do sistema financeiro convencional de ambos países (cujos empréstimos não são acessíveis aos pequenos tomadores) ${ }^{31}$; c) os custos operacionais dos programas são determinantes para estipulação da taxa de juros de um programa auto-sustentável; neste caso, os bancos comerciais embora apresentem ganhos de escala, contam com custos operacionais maiores, não conseguindo reduzir suas taxas de juros abaixo daquelas praticadas por $\mathrm{ONGs}^{32}$; d) segundo estudo do Banco Mundial, todos os programas estão orientados para atingir sustentabilidade operacional e financeira. Os programas bolivianos, um grande número de CEAPEs e a Portosol já teriam atingido a auto-sustentabilidade operacional (definida como receita operacional/despesa operacional maior que um). Já com relação à sustentabilidade financeira, somente o Bancosol e a Caja Los Andes teriam-na alcançado. As ONGs ainda não, porém não se encontrariam muito distante desta meta (Schoenberg, 2000) ${ }^{33}$; e) com relação à taxa de inadimplência, com exceção do Bancosol todos os programas apresentam índices abaixo de 5\%, compatível com o observado nos principais programas de microcrédito do mundo, sem comprometimento de suas carteiras ${ }^{34}$; o Bancosol, entretanto, ostenta taxa de 7\%, apontando uma troca entre crescimento do programa e aumento dos casos de inadimplência.

\footnotetext{
${ }^{30}$ Schoenberg, 2000, levantou que no período correspondente à sua pesquisa, uma financiadora de Porto Alegre cobrava $81,8 \%$ ao ano; $6,8 \%$ ao mês.

${ }^{31}$ No caso brasileiro, as taxas de juros praticadas por estas organizações de microcrédito também são consistentes com aquelas cobradas por bancos e financeiras para empréstimos de consumo. Financiadoras brasileiras neste período praticavam taxas de $81,8 \%$ ao ano ou 6,8\% ao mês (Schoenberg, 2000).

${ }^{32}$ No caso do CrediAmigo, Bancosol e Caja Los Andes, conta-se por exemplo com guichês bancários para desembolsos e reembolsos. Os serviços de microcrédito das ONGs realizam seus desembolsos através de cheques que são descontados em bancos comerciais. Estes serviços acabam gerando custos operacionais maiores, que consomem os ganhos financeiros de escala destes programas, não possibilitando a redução das taxas de juros (Schoenberg, 2000).

${ }^{33}$ Com relação ao CrediAmigo, estando sua contabilidade vinculada com o BNB, informações quanto à sustentabilidade financeira não estão disponíveis. Especialistas presumem, entretanto, que o programa não teria atingido a auto-sustentabilidade financeira (Schoenberg, 2000).

${ }^{34}$ Para acompanhamento das taxas de juros e auto-sustentabilidade dos programas, ver Ledgerwood, 1999.
} 
A seguir, é apresentado um quadro síntese com informações dos programas brasileiros e bolivianos, com relação aos dois parâmetros propostos para caracterizar a sustentabilidade dos programas (com relação ao primeiro, os programas foram agrupados entre aqueles que atingiram somente a auto-sustentabilidade administrativa e a administrativo/financeira; com relação ao segundo, os programas foram agrupados a partir de quartis):

Quadro (4.4) - Sustentabilidade - Parâmetros

\begin{tabular}{|c|l|}
\hline SUSTENTABILIDADE & \multicolumn{1}{|c|}{ Programas } \\
\hline Auto-sustentabilidade Obtida & \\
\hline administrativa & FENAPE, CrediAmigo, Portosol, PRODEM \\
\hline administrativa e financeira & Bancosol, Caja Los Andes \\
\hline Taxa de Inadimplência Incorrida & \\
\hline 10. Quartil (até 2,5\%) & PRODEM \\
\hline 2o. Quartil (até 5,0\%) & FENAPE, Portosol, CrediAmigo, Caja L. Andes \\
\hline 3o. Quartil (até 7,5\%) & Bancosol \\
\hline 4o. Quartil (até 10,0\%) & \\
\hline
\end{tabular}

e) massificação: Como desenvolvido anteriormente (Capítulo II), a capacidade de expansão dos programas de microcrédito está condicionada a alguns parâmetros já exploradas em critérios anteriores, como: a) adoção de metodologia de microcrédito adequada; b) cultura voltada à sustentabilidade dos programas. Outras variáveis poderiam ser adicionadas a estas, relacionadas ao ambiente institucional em que se desenvolvem as atividades de microcrédito, como principalmente: a) existência de regulamentação condizente à expansão do microcrédito; b) existência de outros programas públicos e/ou subsidiados de crédito popular, concorrentes dos programas de microcrédito. Sendo que os dois primeiros parâmetros já foram tratados anteriormente, são propostos como parâmetros relacionados à massificação: i) tamanho da clientela ativa vigente nos programas de microcrédito selecionado, vis a vis quantidade de possíveis tomadores; ii) ambiente institucional em que se inserem os programas, propício ou não ao desenvolvimento da atividade de microcrédito.

Com relação ao tamanho da clientela ativa dos programas, vis a vis quantidade de possíveis tomadores, variável que permite inferir qual a cobertura de atendimento atual dos programas selecionados, temos que: a) o Bancosol e Caja Los Andes na Bolívia e o CrediAmigo no Brasil (ainda que seja um programa recente) apresentam clientela atendida maior que os demais (devendo-se isto principalmente à capilaridade das instituições financeiras); b) o bom desempenho da FENAPE, dentre as experiências brasileiras, deve-se em parte a uma interessante estratégia que visa prover as ONGs da rede com alguns benefícios de economia de escala experimentada por bancos 
comerciais, interligando os CEAPEs através do Brasil, assegurando, por exemplo, consistência na qualidade de administração e suporte de treinamento; c) ainda assim, o Prodem, com mesmo tempo de existência que a FENAPE apresenta clientela maior; d) finalmente, o Portosol apresenta uma clientela ativa bem menor que o restante dos programas analisados, por prescindir de estrutura atrelada ao mercado financeiro convencional, ou articulação em rede.

A estimação da quantidade de possíveis tomadores de microcrédito para ambos países permite relativizar a cobertura das experiências dos programas. Assim, esta variável é construída a partir da quantidade total de clientes beneficiados pelos programas enquanto parcela do total de possíveis clientes de microcrédito para cada país. Como proxy para a esta segunda medida foi assumida a quantidade de trabalhadores conta-própria para o Brasil e Bolívia ${ }^{35}$.

A seguir, é apresentado um quadro síntese com informações dos programas brasileiros e bolivianos, com relação aos dois parâmetros estabelecidos para caracterizar a massificação dos programas: $i$ ) tamanho da clientela ativa vigente nos programas de microcrédito selecionado, vis a vis quantidade de possíveis tomadores (número total de clientes do programa/número total de trabalhadores conta-próprias do país respectivo) $)^{36}$; ii) ambiente em que se inserem os programas, propício ou não ao desenvolvimento da atividade de microcrédito. No primeiro, os programas foram agrupados a partir de quartis. No segundo, os programas foram agrupados segundo ambientes mais ou menos propício ao desenvolvimento da atividade de microcrédito. $\mathrm{O}$ ambiente mais propício foi caracterizado como sendo o que possui regulamentação com maior autonomia para as organizações de microcrédito captarem recursos e desenvolverem outros serviços financeiros como poupança, além de apresentar menor concorrência de programas de crédito popular subsidiados.

\footnotetext{
${ }^{35}$ As informações sobre total de trabalhadores conta-próprias para Brasil e Bolívia utilizadas referem-se ao ano de 1999, sendo suas fontes: IPEA, PNAD para Brasil e UDAPE, Instituto Nacional de Estadística para a Bolívia. As medidas absolutas foram: 1.489.959 trabalhadores conta-próprias na Bolívia e 16.064.062 trabalhadores conta-próprias no Brasil.

${ }^{36}$ Esta variável apresenta o seguinte cálculo: número de clientes atendidos pelos programas: Portosol (2.383), FENAPE (23.310), BNB/CrediAmigo (36.786), Bancosol (73.073), PRODEM (39.909), Caja Los Andes (36.815); número absoluto de trabalhadores por conta-própria Brasil (16.064.062), Bolívia (1.489.959); cobertura dos programas (total de clientes atendidos/número absoluto de trabalhadores conta-próprias no país respectivo: Portosol (0,015\%), FENAPE (0,145\%), BNB/CrediAmigo (0,229\%), Bancosol (4,904\%), PRODEM (2,679\%), Caja Los Andes (2,471\%).
} 
Quadro (4.5) - Massificação - Parâmetros

\begin{tabular}{|c|l|}
\hline MASSIFICAÇÃO & \multicolumn{1}{|c|}{ Programas } \\
\hline Cobertura & \\
\hline 1o. Quartil (de 0 até 1,25\%) & Portosol, FENAPE, CrediAmigo \\
\hline 2o. Quartil (de 1,25\% até 2,5\%) & Caja Los Andes \\
\hline 3o. Quartil (de 2,5\% até 3,75\%) & PRODEM \\
\hline 4o. Quartil (de 3,75\% até 5,0\%) & Bancosol \\
\hline Ambiente da Atividade de Microcrédito & \\
\hline mais favorável & Bancosol, PRODEM, Caja Los Andes \\
\hline menos favorável & FENAPE, CrediAmigo, Portosol \\
\hline
\end{tabular}

\subsection{Construção do Indicador de Eficácia}

Com relação ao foco, o indicador intermediário é composto por dois parâmetros de eficácia: i) estabelecimento ou não de critérios de seleção da população-alvo (rendimento familiar, posses, gênero, etc.) - sendo mais bem ordenados aqueles programas que estabelecem critérios; ii) valor médio de empréstimos concedidos pelos programas - sendo melhor ordenados os programas que apresentam menores valores médios (conforme agrupamento por quartil).

Com relação à composição de fundos, dois parâmetros de eficácia compõem este indicador intermediário: i) tamanho da carteira dos programas de microcrédito selecionados - sendo melhor ordenados os programas que apresentam maiores valores (por quartil); ii) capacidade de diversificação e expansão da carteira, segundo prerrogativas garantidas pela legislação vigente (doações, financiamentos e poupança) - sendo melhor ordenados os programas que apresentam mais opções de diversificação e expansão da carteira, amparados pela regulamentação.

Com relação à combinação de instrumentos, a ordenação foi estabelecida para ambos parâmetros de eficácia conforme: i) utilização de instrumentos de microcrédito combinados - sendo mais bem ordenados os programas que utilizam o maior número de instrumentos de microcrédito em sua metodologia; ii) oferecimento de outros serviços de apoio ao empreendimento - sendo mais bem ordenados aqueles programas que oferecem outros serviços de apoio ao empreendimento (levando-se em consideração que esta atividade adicional é apenas subsidiária à atividade de concessão de crédito, não prejudicando a sustentabilidade dos programas).

Com relação à sustentabilidade, a ordenação foi estabelecida para os dois parâmetros, conforme: i) obtenção ou não de auto-sustentabilidade administrativa elou financeira dos programas (em contraponto a programas subsidiados) - sendo melhor 
ordenados os programas que tenham atingido sustentabilidade administrativa e financeira; ii) controle da taxa de inadimplência, para que não comprometa a sustentabilidade dos programas - sendo melhor ordenados os programas que apresentem menores taxas de inadimplência, por quartil.

Com relação à massificação, a ordenação foi estabelecida para os dois parâmetros contemplados conforme: i) tamanho da clientela ativa vigente nos programas de microcrédito selecionado, vis a vis quantidade de possíveis tomadores sendo mais bem ordenados os programas que apresentem maior clientela ativa, por quartil; ii) ambiente em que se inserem os programas, propícios ou não ao desenvolvimento da atividade de microcrédito - sendo mais bem ordenados os programas que se insiram em ambientes mais favoráveis para a expansão da atividade de microcrédito.

Conforme metodologia explicitada na primeira seção deste, no quadro a seguir agregam-se as ordenações dos programas selecionados a partir dos indicadores intermediários dos cinco critérios de avaliação analisados, obtendo-se para cada programa valores ordinais conforme a tabela que segue. Por extensão, são os indicadores de eficácia que permitem a sistematização de uma avaliação comparativa, construídos para os dois países, Brasil e Bolívia:

Quadro (4.6) - Construção do Indicador de Eficácia

\begin{tabular}{|c|c|c|c|c|c|c|}
\hline Critérios/Programas & FENAPE (BR) & CrediAmigo (BR) & Portosol (BR) & Bancosol (BO) & PRODEM (BO) & Caja L. Andes (BO) \\
\hline FOCO Soma de Pontos & 3 & 2 & 4 & 5 & 2 & 4 \\
\hline FOCO Ordenação & 2 & 1 & 3 & 4 & 1 & 3 \\
\hline Tamanho da Carteira & 3 & 3 & 3 & 1 & 2 & 2 \\
\hline Formas de Captação & 3 & 2 & 3 & 1 & 3 & 1 \\
\hline COMP. FUNDOS Soma de Pontos & 6 & 5 & 6 & 2 & 5 & 3 \\
\hline COMP. FUNDOS Ordenação & 4 & 3 & 4 & 1 & 3 & 2 \\
\hline COMB. INSTRUM. Soma de Pontos & 2 & 3 & 2 & 3 & 2 & 5 \\
\hline COMB. INSTRUM. Ordenação & 1 & 2 & 1 & 2 & 1 & 3 \\
\hline Auto-Sustentabilidade Obtida & 2 & 2 & 2 & 1 & 2 & 1 \\
\hline Taxa de Inadimplência Incorrida & 2 & 2 & 2 & 3 & 1 & 2 \\
\hline SUSTENTABILIDADE Soma de Pontos & 4 & 4 & 4 & 4 & 3 & 3 \\
\hline SUSTENTABILIDADE Ordenação & 2 & 2 & 2 & 2 & 1 & 1 \\
\hline INDICADOR DE EFICÁCIA & \multicolumn{3}{|c|}{ Brasil - 39 pontos } & \multicolumn{3}{|c|}{ Bolívia 30 pontos } \\
\hline
\end{tabular}


Especificamente, os indicadores construídos permitem inferir que com relação à contribuição de cada critério na composição dos indicadores, o conjunto de programas brasileiros levam vantagem sobre os bolivianos nos critérios foco (somando 5 pontos contra 8) e combinação de instrumentos (somando 4 pontos contra 6). Os programas bolivianos superam os brasileiros nos demais critérios: composição de fundos (somando 6 pontos contra 11), sustentabilidade (somando 4 pontos contra 6) e massificação (somando 6 pontos contra 12).

Com relação à contribuição de cada programa selecionado na composição do indicador, observamos que a avaliação de todos os programas bolivianos sugerem maior eficácia que os programas brasileiros, com exceção da Caja Los Andes (programa boliviano pior avaliado) que apresenta mesma pontuação que o CrediAmigo (programa brasileiro melhor avaliado). Já com relação ao peso relativo do arcabouço institucional que envolve os programas de microcrédito na construção do indicador, cabe ressaltar que interferem principalmente nos critérios de massificação e sustentabilidade. Em ambos, os programas bolivianos apresentaram eficácia maior que os brasileiros, sugerindo sua maior contribuição para o desenvolvimento das atividades de microcrédito para aquele país.

Finalmente, com relação ao atual estágio de expansão da atividade de microcrédito dos dois países, que interfere principalmente nos critérios de composição dos fundos e massificação, observa-se novamente a superioridade dos resultados bolivianos (são os dois critérios que apresentam maior discrepância entre a pontuação dos dois países), atestando o desnível entre ambas experiências com relação principalmente ao volume total de crédito disponibilizado e quantidade de operações de microcrédito efetuadas. Estas considerações de âmbito geral e específico permitirão uma análise mais pormenorizada e aderente aos arcabouços institucionais e ao panorama das atividades de microcrédito.

\section{Considerações finais}

Neste artigo, o microcrédito foi analisado como serviço creditício capaz de inserir no mercado de crédito parcelas da população de baixa renda que carecem de alternativas para obter crédito e alavancar suas atividades produtivas. Os programas de microcrédito ocupam nicho ainda não perfeitamente institucionalizado nos sistemas 
financeiros convencionais dos países analisados, mesclando características e motivações típicas de instituições financeiras, quanto de políticas públicas de emprego. Estes serviços permitem que sejam atendidos pequenos empreendimentos e o setor informal da economia, ao proporem inovadoras formas de operacionalização das carteiras com relação à seleção de clientes, avaliação de riscos e exigência de garantias. Apresentam assim soluções para os problemas de seleção adversa e risco moral, decorrentes da assimetria de informação subjacente ao mercado de crédito, e que são responsáveis por seu racionamento. Ademais, permitem baratear elevados custos operacionais resultantes de estratégias das instituições financeiras para dirimir os problemas de assimetria de informação, que as coíbem de operarem linhas de crédito para populações de baixa renda.

Assim, as organizações de microcrédito foram caracterizadas por instrumentos concebidos para adequação das estruturas de administração de carteira viabilizando o acompanhamento de empréstimos de pequena monta, utilização de contratos de empréstimos que eliminem a necessidade de contrapartidas reais como forma de garantia, dedicação de uma nova abordagem ao foco da sua clientela, priorizando grupos comunitários e o gênero feminino, entre outros. Este trabalho procurou destacar os principais instrumentos típicos do microcrédito, relacionando-os com os problemas de assimetria de informação subjacente ao mercado de crédito: aval solidário, monitoramento mútuo, incentivos progressivos, atuação no âmbito local, priorização do gênero feminino, parcelamento do pagamento em períodos curtos e garantias alternativas, o que permitiu a proposição e construção de um indicador de eficácia comparativa entre os programas brasileiro e boliviano.

De modo geral, os coeficientes obtidos por este indicador permitiram avaliar que a atividade de microcrédito boliviana encontra-se de fato em estágio de maior desenvolvimento. Especificamente, observou-se que os programas bolivianos analisados levam vantagem em relação aos critérios composição de fundos, sustentabilidade e massificação, enquanto os programas brasileiros estão mais bem avaliados nos critérios foco e combinação de instrumentos.

Estes resultados sugerem que no atual estágio de desenvolvimento da atividade boliviana, a preocupação em tornar os programas de microcrédito massivos, com précondição de serem auto-sustentáveis, vem superando paulatinamente o princípio de que deveriam atender exclusivamente as populações de mais baixa renda. Como foi 
discutido no trabalho, parece haver uma tendência progressiva de inserção das atividades de microcrédito no sistema financeiro convencional daquele país em detrimento dos serviços de microcrédito operados por ONGs, que tendem a garantir melhor focalização dos programas. A lógica financeira de auto-sustentabilidade estaria impelindo os programas de microcrédito bolivianos a beneficiar parcelas da população cada vez menos pobres, desvirtuando em parte o foco inicial desta atividade. No Brasil, o impulsionamento tardio da atividade de microcrédito, principalmente através de esforços claudicantes do poder público brasileiro, não garantiu sucesso na massificação da atividade. Por outro lado, a relativa importância das ONGs no cenário da oferta de microcrédito no Brasil aliada à insipiência de seu atrelamento ao sistema financeiro convencional, acabam por permitir uma melhor focalização dos programas analisados. Assim, um entendimento mais aprofundado a respeito do arcabouço institucional em que se desenvolvem as atividades de microcrédito nos dois países é fundamental para a interpretação dos resultados obtidos.

O peso relativo do arcabouço institucional que envolve os programas de microcrédito na construção do indicador proposto interfere principalmente nos critérios de massificação e sustentabilidade, onde os programas bolivianos apresentaram eficácia maior que os brasileiros. Os programas de microcrédito brasileiros foram desenvolvidos a partir de iniciativas de origem privada e pública, assumindo ambas similar importância no desenvolvimento desta atividade no Brasil, ainda que em períodos distintos. Já os programas de microcrédito bolivianos desenvolveram-se a partir de iniciativas exclusivamente privadas, sendo que seu arranjo institucional limita-se a experiências com este cunho.

Posto que ambas experiências forma iniciadas em período similar (final da década de 1980), observam-se no arranjo boliviano resultados mais massivos, devido à sua rápida e facilitada conexão com o sistema financeiro convencional. Além do estabelecimento de um banco comercial totalmente orientado para atividades de microcrédito, o Bancosol, coube ser destacado no trabalho o desenvolvimento de instituições financeiras privadas de segunda ordem, articuladas ou não com o poder público, especializadas em financiar programas de microcrédito, imprescindíveis para a expansão desta atividade. Este arranjo boliviano não encontra correspondência na experiência brasileira. 
Porém, ressaltou-se também que o sistema financeiro convencional brasileiro é muito mais desenvolvido e complexo que o boliviano. O crescimento consistente da atividade de microcrédito na Bolívia se deu em parte devido à desestruturação de seu sistema financeiro. A própria necessidade recente de reformulação profunda das normas do sistema financeiro combalido (por parte do Banco Central e sua Superintendência dos Bancos), permitiram acomodar melhor os novos serviços de microcrédito emergentes. No caso brasileiro, o Banco Central impõe regras mais rígidas para o ingresso e operação de instituições financeiras, considerando o sistema suficientemente saturado. Embora tenha sinalizado com boas intenções apoiar o desenvolvimento de atividades de microcrédito no país, é possível crer que a regulamentação destas atividades se dará de forma bem menos dinâmica que no caso boliviano, e que pode se tornar fator impeditivo para uma maior massificação e auto-sustentação dos programas brasileiros em curto e médio prazo.

Os avanços conseguidos no panorama da oferta de microcrédito no Brasil, com a institucionalização das SCMs (Sociedades de Crédito ao Microempreendedor), podem ser considerados ainda incipientes, posto que não potencializam sua capacidade de obter fundos via captação de depósitos e oferecimento de novos serviços financeiros. Embora o capital inicial mínimo necessário para o estabelecimento de uma SCM seja muito menor do que aquele exigido para um FFP (Fundo Financeiro Privado), financeiras bolivianas regulamentadas especializadas em microcrédito que também têm permissão legal de captar recursos junto ao público, inferindo-se uma proliferação de SCMs mais veloz do que se observou com relação aos FFPs, o que se observou na prática foi um lento crescimento destas organizações, inibido principalmente pela impossibilidade de captação junto ao público e supervisão excessiva do Banco Central. O Banco Central brasileiro exige uma série de informações financeiras regularmente das SCMs, aumentando seu custo de operação. Outras alternativas privadas de concessão de crédito no Brasil, como factorings e cartão de crédito não são regulamentadas e nem supervisionadas pelo Banco Central, tornando-se mais atraentes como formatos jurídicos para os agentes de mercado financeiro.

Estes condicionantes institucionais obviamente impactam na eficácia dos programas analisados. O indicador construído permitiu avaliar que, individualmente, todos os programas bolivianos apresentam maior eficácia que os brasileiros. A superioridade dos resultados individuais dos programas bolivianos fica mais evidente 
justamente nos critérios relacionados à composição de fundos, massificação e sustentabilidade, ressaltando o desnível entre os dois países com relação principalmente ao volume total de crédito disponibilizado e quantidade de operações de microcrédito efetuadas.

Não deve ser desconsiderada, entretanto, a importância crescente de atuação da esfera pública brasileira junto à atividade de microcrédito. Ressaltou-se sua significativa intervenção direta nesta atividade na última década, destacando seu papel de política pública de emprego e a sinergia que provocou no terceiro setor ao organizar entidades mistas, de controle público e cunho privado. Coube ainda ser destacado o papel articulador, financiador e regulador do poder público brasileiro, embora ainda bastante incipiente, que apresenta tendência de substituir paulatinamente a intervenção direta que o poder público realizou na última década. A participação do poder público boliviano no arranjo institucional das atividades de microcrédito neste país é indireta, não se observando intervenções diretas de concessão de crédito à população de baixa renda, apenas algum papel de promoção dos programas enquanto agente financiador de segunda ordem. Contudo, o papel regulador do poder público boliviano foi fundamental para garantir a massificação do microcrédito naquele país.

Por fim, é importante ressaltar que instrumentos de avaliação dos programas de microcrédito encontram espaço cada vez mais amplo nesta respectiva literatura, ainda que a maior parte dos estudos esteja ainda voltada à análise dos programas sob a ótica de sua eficiência financeira e operacional. Este trabalho procurou contribuir com o entendimento e avaliação do microcrédito a partir da ótica de sua inserção em ambientes institucionais que conjugam estratégias de políticas públicas e de iniciativas privadas do sistema financeiro regulamentado ou não. Ressalte-se ainda a importância de se proceder a avanços em trabalhos que permitam avaliar o impacto do microcrédito na geração de renda e crescimento da atividade econômica de seus tomadores, o que complementaria a avaliação da eficácia desta atividade, agora sob a ótica da demanda (ou seu impacto sócio-econômico local), que não foi objeto deste estudo. Assim sendo, é importante frisar que o indicador proposto, resultante da avaliação comparativa procedida para as atividades de microcrédito no Brasil e Bolívia, pretendeu contribuir para o entendimento da evolução do microcrédito, possibilitando uma sistematização de como se estrutura a oferta de microcrédito nos países analisados, e sua consonância com 
os instrumentos típicos do microcrédito que dirimem problemas de assimetria de informação no mercado de crédito.

\section{Referências Bibliográficas}

ARRIOLA, P. Evolución de Las Microfinanzas en Bolivia. La Paz: Caja de Los Andes, 2000.

AZEREDO, B. Políticas Públicas de Emprego: A Experiência Brasileira. São Paulo: ABET - Associação Brasileira de Estudos de Trabalho, 1998.

BID (Banco Interamericano de Desenvolvimento). Social Tensions and Social Reforms. In: Social Agenda Policy Group. Washington DC, 1994.

BANCO MUNDIAL. Relatório sobre o Desenvolvimento Mundial: O Estado num mundo em Transformação. Washington DC: Banco Mundial, 1997.

BRAGA, M. B. \& TONETO JR, R. Microcrédito: Aspectos Teóricos e Experiências. Revista Análise Econômica. UFRGS, ano 18, n. 33, mar/2000.

BRAGA. M. B. Algumas considerações teóricas e implicações decorrentes da relação contratual entre credor e devedor sob a hipótese de existência de assimetria de informação. In: Anais da ANPEC, 1999.

CACCIAMALI, M. C. et al. Crescimento Econômico e Geração de Empregos: Considerações sobre Políticas Públicas. In: Planejamento e Políticas Públicas, número 12. Brasília: IPEA - Instituto de Pesquisa Econômica Aplicada, 1995.

COMUNIDADE SOLIDÁRIA. A Expansão do Microcrédito no Brasil. Documento Base da VI Reunião do Conselho da Comunidade Solidária, Brasília, 2001.

FAlCONER, A. A Promessa do Terceiro Setor. 1999. Dissertação de Mestrado, Depto. de Administração FEA/USP, São Paulo.

FIDLER, P. Assessing the Performance of Banco Solidario S.A. as a Provider of Micro-Finance. Case Studies in Microfinance, World Bank, 1998.

FUENZALIDA, E. Por qué los Programas de Crédito no son Masivos? In: Lecciones sobre Credito al Sector Informal Urbano. Santiago: PREALC/OIT, 1990.

FUNDA-PRÓ. The Development of Microfinance in Bolivia. La Paz, 1999.

GARSON, J. Microfinance and Anti-Poverty Strategies - A Donor Perspective. Washington DC: UNCDF, 1998.

GERMIDIS, D. Financial Systems and Development: What Role for the Formal and Informal Financial Sectors? Paris: OCDE, Development Centre Studies, 1991. 
GOLDMARK, L.; POCKROSS, S; VECHINA, D. A Situação das Microfinanças no Brasil. Projeto BNDES-BID de Microfinanças, Rio de Janeiro, 2000.

IBASE (Instituto Brasileiro de Análises Sociais e Econômicas). Democracia Viva. Rio de Janeiro, 1998.

IPEA (Instituto de Pesquisas Econômicas Aplicadas). Estimativa do Público Potencial do Microcrédito Produtivo Popular. Brasília DF, 1999.

KATSUMA, Y. Transforming na NGO into a Commercial Bank to Expand Financial Services for the Microenterproses of Low-Income People. University of Wisconsin at Madison, USA, 1998.

KLEIN, E. Crédito, Heterogeinidad y Pobreza. In: Lecciones sobre Credito al Sector Informal Urbano. Santiago: PREALC/OIT, 1990.

LEDGERWOOD, J. Microfinance Handbook: An Institutional and Financial Perspective. Washington DC: World Bank, 1999.

LEE, E. Globalization and Employment: Is Anxiety Justified? In: International Labour Review, USA, v. 135, n. 6, 1996.

LEVITSKY, J. World Bank Lending to small Enterprises. Washington DC: World Bank, 1986.

LOYASA, M. Gasto Público Social en La Década de Los Noventa. In: Revista de Investigación Económica, v. 17, La Paz: Udape, set/1999.

MEZZERA, J. Modas y Profesionalismo: La Financiación del Sector Informal Urbano. In: Credito Informal: Acceso al Sistema Financiero. Santiago: PREALC/OIT, 1993.

MTB (Ministério do Trabalho). Avaliação Sintética do Proger no ano de 1998. Brasília DF, 1998.

Brasília DF, 2000.

Informações Gerenciais da Coordenação Geral de Emprego (CGEM).

MORDUCH, J. The Microfinance Promise. In: Journal of Economic Literature, v. 37, USA, dec/1999.

NAPP (Núcleo de Assessoria de Planejamento e Pesquisa). Avaliação do Programa do CEAPE/PE. Rio de Janeiro, 1996.

OIT (Organização Internacional do Trabalho). El Empleo en el Mundo, 1996/1997 - Las Politicas Nacionales en la Era de la Mundializacion. Genebra, 1996.

PASSOS, A.; PAIVA, L. H. \& CONSTANZI, R. Microcrédito: questões para a política social. In: Informações FIPE, n. 250, São Paulo, jul/2001.

POCHMANN, M. As Políticas de Geração de Emprego e Renda: Experiências Internacionais Recentes. In: Reforma do Estado e Políticas de Emprego no Brasil. Campinas: IE/UNICAMP, 1998. 
RESENDE, L. Sistemas Banco do Povo: uma proposta. Brasília: IPEA, 1995.

RAMOS, C. A. Sistemas públicos de Emprego: a Experiência de Três Países da OCDE (Espanha, EUA e Alemanha). Texto para Discussão, n. 511. Brasília: IPEA, 1997.

RIMA, I. Labor Markets in a Global Economy. Nova York: M. E. Sharpe, 1996.

ROSALES, R. Marco Jurídico para as Instituições de Microcrédito. USA: International Consulting Corporation, 2000.

SCHOENBERG, S. Microfinance Prospects in Brazil. Washington DC: Banco Mundial, 2000.

STIGLITZ, J. e WEISS, A. Credit Rationing in Markets with Imperfect Information. In: American Economics Review, USA, v. 71, n. 3, 1981.

STIGLITZ, J. E. Governo, Mercado Financeiro e Desenvolvimento Econômico. In: Revista Brasileira de Economia, v. 44, n. 03, 1990.

USAID (U.S. Agency for International Development). FY2000 Microenterprise Implementation Grant Program for Business Development Services. Washington DC, 1999.

UDAPE (Unidad de Análisis de Politicas Sociales y Económicas). Evaluación Económica de 1999. La Paz, 1999.

UNDP (United Nations Development Program). Human Development Report. United Nations, 1999.

VARIAN, H. R. Microeconomia: Princípios Básicos. Rio de Janeiro: Editora Campus, 2000.

VON STOCKHAUSEN, J. The Role of Non-Governamental Organizations for Financial Markets. In: Savings and Development, v. XI, n. 02, USA, 1998.

YUNUS, M. O banqueiro dos pobres. São Paulo: Editora Ática, 2000. 